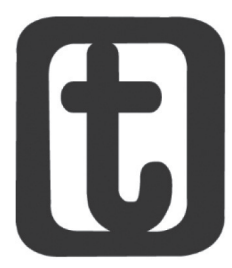

\title{
A PARTICIPAÇÃO EM ESPAÇOS COLETIVOS E A AUTONOMIA DOS IDOSOS
}

\author{
PARTICIPATION IN COLLECTIVE SPACES AND \\ AUTONOMY OF THE ELDERLY

\section{Rosane Bernardete Brochier Kist ${ }^{1}$ Leonia Capaverde Bulla²}

\section{RESUMO}

Este artigo discute uma pesquisa que teve como objetivo analisar a participação de idosos em grupos de convivência e sua contribuição à garantia de seus direitos e de sua autonomia. A coleta de dados realizou-se junto a grupos de idosos vinculados à Prefeitura Municipal de Porto Alegre e a duas universidades, uma pública e outra privada. Optou-se pelo método dialético-crítico e pelo enfoque qualitativo, utilizando-se como técnicas de pesquisa a entrevista semiestruturada, a

1 Assistente Social (UNISC, RS). Mestre e Doutora em Serviço Social pela Pontifícia Universidade Católica do Rio Grande do Sul (PUCRS). Doutorado sanduíche (PDEE/CAPES) e Especialização em Psicomotricidade na Universidade de Barcelona, Espanha. Pós-doutoranda inserida no Programa de Bolsas de PósDoutorado - DOCFIX (FAPERGS/CAPES), ligada ao Programa de Pós-Graduação em Desenvolvimento Regional da Universidade de Santa Cruz do Sul (UNISC) RS). Integrante do Grupo de Pesquisa "Realidade Exclusão e Cidadania na Terceira Idade" (CNPq/UNISC). E-mail: rosanekist2009@hotmail.com. E-mail: rosanekist2009@hotmail.com

2 Assistente Social (UFSC); Mestre em Serviço Social (Université Laval, Quebec, Canadá); Doutora em Ciências Humanas: Educação (Faculdade de Educação da UFRGS); Pós-Doutora em Serviço Social (Universidade de Kassel, Alemanha). Professora da Faculdade de Serviço Social da PUCRS (Graduação, Mestrado e Doutorado). Coordenadora do Núcleo de Pesquisas em Demandas e Políticas Sociais e do Grupo de Pesquisas em Gerontologia Social da PUCRS. Consultora Ad Hoc e Pesquisadora nível $1 \mathrm{~B}$ do Conselho Nacional de Desenvolvimento Científico e Tecnológico (CNPq). Consultora Ad Hoc da Coordenação de Aperfeiçoamento de Pessoal do Ensino Superior (CAPES). Membro do Comitê Interdisciplinar da Fundação de Amparo à Pesquisa do Rio Grande do Sul (FAPERGS). E-mail: Ibulla@pucrs.br.E-mail: Ibulla@pucrs.br 


\section{temporalis}

observação aberta e a pesquisa documental. Todos os entrevistados assinaram o formulário e o termo de Consentimento Livre e Esclarecido. Constatou-se que a participação dos idosos nos grupos analisados lhes oportuniza inúmeros benefícios e contribui para a realização de processos coletivos que estimulam o exercício pleno da cidadania, garantindo sua autonomia e a melhoria de sua qualidade de vida.

Palavras-chave: Participação Social. Autonomia. Garantia de direitos.

\section{ABSTRACT}

This paper discusses a study that aimed to examine the participation of older people in companionship groups and their contribution to the guarantee of their rights and their autonomy. Data collection took place with groups of older people linked to the Municipality of Porto Alegre and to two universities, one public and other private. We opted for dialectical-critical method and for qualitative approach, using as research techniques the semi-structured interview, the open observation and the documentary research. All participants signed the form and the term of Free and Informed Consent. It was found that the participation of the elderly in the analyzed groups gives them opportunity to numerous benefits and contributes to the achievement of collective processes which stimulate full exercise of citizenship, assuring their autonomy and the improvement of their quality of life.

Keywords: Social Participation. Autonomy. Assurance of rights.

Submetido em 24/06/2014

Aceito em 18/09/2014

\section{INTRODUÇÃO}

A preocupação com o tema do envelhecimento demográfico da população é recorrente nas sociedades em nível mundial, tanto daquelas consideradas como desenvolvidas quanto das que se encontram em vias de desenvolvimento. Estudos que envolvem o período entre 1950 e 2050 apontam uma projeção em nível europeu que evidencia o incremento da porcentagem de pessoas idosas nas sociedades, ao mesmo tempo que existe uma diminuição crescente da população geral (ZAIDI, 2008).

Nos países latino-americanos e, especialmente, no Brasil, a situação é muito semelhante, pois, a partir das estatísticas, acredita-se que o país passe a ocupar um dos primeiros lugares no ranking mundial, no período que anteceda o indicado pelas 
projeções demográficas. Em 1999, a população idosa brasileira com 60 anos ou mais correspondia a 9,1\% (IBGE, 2010), aumentando para 10,5\% no ano de 2007 (IBGE, 2008). Em 2008, essa população subiu para 21 milhões de pessoas, correspondentes a $11,1 \%$ da população total, concentradas, especialmente, nos estados do Rio de Janeiro (14,9\%) e do Rio Grande do Sul (13,5\%) (IBGE, 2009). Os dados do IBGE (2010) evidenciam um total de $11,3 \%$ de brasileiros com 60 anos ou mais.

Os dados demográficos comprovam que o aumento da expectativa de vida das pessoas significa um êxito e o surgimento de novas oportunidades para as sociedades atuais. Entretanto, o envelhecimento das populações é um tema que requer, cada vez mais, uma qualificação das pessoas idosas e dos indivíduos envolvidos, do setor privado e das instituições, assim como exige a reformulação das políticas públicas que devem apresentar respostas e soluções para esse desafio que se apresenta.

A sociedade atual apresenta uma contradição, que se expressa pela possibilidade de crescimento significativo da população idosa, ao mesmo tempo que convive paradoxalmente com situações de omissão, de preconceito e até mesmo de abandono. Evidenciam-se esforços no sentido de prolongar a vida dos cidadãos, entretanto, existe um grande desafio no sentido de garantir que os idosos sejam reconhecidos como sujeitos autônomos e capazes de um exercício pleno de sua cidadania.

Ressalta-se a relevância acadêmica da referida investigação, tendo-se em vista que, historicamente, o Serviço Social, enquanto área do conhecimento, tem privilegiado a pesquisa, tanto para a formação, evidenciando a capacidade investigativa na graduação, quanto para a formação de pesquisadores na pós-graduação, além de atribuir-lhe um papel privilegiado na compreensão e na solução de problemas sociais (CARVALHO, 2005).

Como salienta Guerra (2009), a pesquisa garante ao Serviço Social o estatuto de maioridade intelectual, pois possibilita uma contribuição efetiva às diversas áreas do conhecimento e uma conexão (através de múltiplas mediações) com as demandas da classe trabalhadora, o que garante uma legitimidade à profissão. 


\section{temporalis}

A pesquisa possibilita ao profissional a identificação de estratégias que possam instrumentalizar e orientar sua ação, contribuindo para o atendimento das demandas e sua reconstrução crítica. Ela possui um papel decisivo, tanto nos processos de qualificação da intervenção profissional quanto na ampliação da produção intelectual e bibliográfica da profissão, em especial aquela produzida a partir da pós-graduação stricto sensu.

No tópico que segue, será apresentado, inicialmente, o processo metodológico da pesquisa realizada com idosos que participam de grupos ligados à Fundação de Assistência Social e Cidadania (FASC) da Prefeitura Municipal de Porto Alegre e de grupos ligados às universidades, Pontifícia Universidade Católica do Rio Grande do Sul (PUCRS) e Universidade Federal do Rio Grande do Sul (UFRGS). Será dada ênfase à possibilidade da garantia da autonomia dos idosos que participam de espaços coletivos, conforme evidenciado no estudo.

\section{PRESSUPOSTOS EPISTEMOLÓGICOS E METODOLÓGICOS}

A referida pesquisa teve como referência o método dialético-crítico, que consiste na análise do homem enquanto sujeito inserido numa realidade social "concebida como efetivo espaço de luta de classes" (CURY, 1985, p. 13), constituída através de um processo histórico e contraditório, em constante transformação, necessitando ser desvelada na sua totalidade para que haja apreensão, conhecimento, reflexão e transformação do real. Com base nas categorias teórico-metodológicas que integram o método dialético-crítico, a contradição, a totalidade, a mediação e a historicidade, que auxiliaram para a apreensão do real, realizou-se o estudo, por meio de coleta de dados e informações, viabilizando uma maior compreensão sobre o fenômeno do envelhecimento e da velhice e, especialmente, sobre a importância dos processos de participação dos idosos em atividades grupais, tendo em vista a garantia de sua autonomia.

Optou-se pelo enfoque qualitativo da pesquisa, visando compreender o modo de vida dos idosos, o que foi complementado com dados quantitativos, que permitiram a identificação das condições de vida desses homens e mulheres na sociedade atual. Para realização do estudo, delimitou-se geograficamente 
o município de Porto Alegre. Foram entrevistados 12 grupos relacionados à Prefeitura Municipal de Porto Alegre, 9 grupos ligados à Pontifícia Universidade Católica do Rio Grande do Sul e 3 grupos associados à Universidade Federal do Rio Grande do Sul. Totalizou-se, assim, uma amostra de 24 grupos (12 da Prefeitura e 12 de universidades), com 120 idosos e 32 profissionais entrevistados.

No processo de elaboração do projeto de pesquisa, foram considerados dois instrumentos jurídico-formais essenciais, a Lei n. 8.662/1993 (BRASIL, 1993), que regulamenta a profissão e explicita o que o assistente social deve fazer (COUTO, 2009), suas competências e atribuições privativas; e o Código de Ética Profissional (CFESS, 1993), que menciona os valores e princípios éticos fundamentais que devem estar presentes no trabalho realizado.

Consideraram-se, também, as Resoluções n. 196, de 10/10/96, e n. 251, de 07/08/1997, aprovadas pelo Conselho Nacional de Saúde, que disciplinam a pesquisa envolvendo seres humanos, como forma de garantir a proteção dos sujeitos e a defesa da integridade da pesquisa, entre outros aspectos. As referidas Resoluções estão em consonância com a Lei n. 8.662/93 de Regulamentação da Profissão de Assistente Social (BRASIL, 1993) e com o Código de Ética Profissional dos Assistentes Sociais, Resolução CFESS n. 273/93 (BRASIL, 1993).

Como ressaltam Rosa, Costa e Soares (2006), toda pesquisa implica uma relação de poder, na medida em que o pesquisador é quem define o que será estudado e as metodologias que serão adotadas, além de ser o responsável pelo processo de sistematização, organização, apresentação e socialização dos resultados obtidos. A partir da criação da Resolução n. 196/96, ficou evidenciado o reconhecimento dos informantes da pesquisa como sujeitos autônomos e detentores de direitos, no que se refere tanto à sua decisão para participar ou não do estudo quanto aos acordos relativos ao processo de investigação.

Com base nas recomendações citadas, referentes à apreciação dos projetos de pesquisa que envolvam seres humanos e à submissão do protocolo de pesquisa no Comitê de Ética, 


\section{temporalis}

salienta-se que o projeto da pesquisa referida foi submetido inicialmente à avaliação e aprovado pela Comissão Científica da Faculdade de Serviço Social em 16 de dezembro de 2008, tendo sido apreciado e aprovado pelo Comitê de Ética em Pesquisa da PUCRS em 9 de janeiro de 2009.

A coleta de dados ocorreu por intermédio da entrevista, com a utilização de um Termo de Consentimento que visou ao esclarecimento dos sujeitos sobre a finalidade do estudo, o sigilo profissional e a importância da colaboração e participação deles para a referida investigação. Utilizou-se a técnica³ da entrevista semiestruturada ${ }^{4}$, que permite a liberdade para o pesquisador desenvolver cada situação na direção que julgar adequada, e das perguntas abertas, que podem ser respondidas a partir de uma conversação informal. Para a realização das entrevistas, foi usado um instrumento denominado formulário, considerado como um dos instrumentos essenciais para a investigação social, em que se obtêm os dados a partir do contato direto com o entrevistado. Realizaram-se, também, a observação aberta e a pesquisa documental, em documentos considerados como fontes primárias (MARKONI; LAKATOS, 2006), como arquivos públicos e privados, estatísticas, entre outros.

No que se refere à análise dos dados quantitativos, usaram-se técnicas de tratamento estatístico simples para a análise descritiva, de frequência, visando a um aproveitamento dos dados apresentados e sua interpretação. Também foram utilizados gráficos, que se configuram como "figuras que servem para a representação do dado" e que, quando "utilizados com habilidade, podem evidenciar aspectos visuais dos dados de forma clara e de fácil compreensão" (MARCONI; LAKATOS, 2006, p. 38).

A interpretação e a análise dos dados qualitativos advindos das entrevistas realizadas com os idosos e os profissionais ocorreram através da análise de conteúdo, com base em Bardin (1977),

3 Para Severino (2007, p. 124), as técnicas podem ser definidas como "procedimentos operacionais que servem de mediação prática para a realização das pesquisas".

4 Conforme Marconi e Lakatos (2006), esse tipo de entrevista pode ser classificado também como "despadronizada" ou "não estruturada". 
constituídas por três fases distintas: a) organização da análise ou pré-análise, que possibilita a identificação de expressões, palavras e frases significativas e a estruturação das unidades do texto; b) exploração ou codificação, que pressupõe três atividades: a definição das unidades de registro, a enumeração e a categorização, possibilitando a identificação de categorias empíricas que podem ser acrescentadas e o complemento das categorias teórico-temáticas pré-definidas; c) tratamento dos dados e/resultados, em que é possível fazer inferências, identificar os significados e interpretar os dados coletados através de um processo de mediação com a fundamentação teórica.

Ressalta-se a importância da análise de conteúdo para a interpretação dos dados da pesquisa devido à possibilidade do estabelecimento de um significado mais amplo às respostas, vinculando-as a outros conhecimentos. Como referem Marconi e Lakatos (2006, p. 35), a interpretação "[...] significa a exposição do verdadeiro significado do material apresentado, em relação aos objetivos propostos e ao tema. Esclarece não só o significado do material, mas também faz ilações mais amplas dos dados discutidos". Nesse sentido, para ilustrar as reflexões sobre as categorias participação, autonomia e melhoria da qualidade de vida, serão utilizadas algumas falas dos sujeitos entrevistados, a partir de uma amostra previamente definida composta por sujeitos que possuem uma referência grupal e que expressam suas vivências e de seu grupo.

\section{A PARTICIPAÇÃO SOCIAL DOS IDOSOS: PERSPECTIVAS DE GARANTIA DA AUTONOMIA E DE MELHORIA NA QUALIDADE DE VIDA}

Inicialmente, apresentam-se alguns dados relativos ao perfil dos idosos entrevistados que integram grupos ligados à Fundação de Assistência Social e Cidadania (FASC), à Pontifícia Universidade Católica do Rio Grande do Sul (PUCRS) e à Universidade Federal do Rio Grande do Sul (UFRGS)5. Na sequência, será dada ênfase

5 Ressalta-se que nos itens seguintes deste artigo serão utilizadas somente as siglas para identificar as instituições referidas. 


\section{temporalis}

à importância da participação dos idosos em espaços grupais na perspectiva da garantia de sua autonomia ${ }^{6}$.

\section{O perfil dos idosos entrevistados}

Identifica-se um predomínio das mulheres no total de idosos que participam dos grupos analisados, o que representa um total de 95\% (324) dos integrantes dos grupos da FASC e 88\% (429) nos grupos universitários. Constata-se que as mulheres brasileiras representam $55,8 \%$ da população idosa como um todo (IBGE, 2010), percentual que aumenta, se analisado o subgrupo de 80 anos e mais, o que reafirma a expressão de Camarano, Kanso e Mello (2004, p. 29) de que "o mundo dos muito idosos é o mundo das mulheres".

No que concerne às idades dos idosos que participam dos grupos da FASC, a maioria, 57 idosos (95\%), possui idades entre 50 e 80 anos, com uma concentração de 27 idosos (45\%) nas faixas etárias entre 71 e 80 anos. Do total de idosos que têm entre 50 e 80 anos, apenas 3 deles (5\%) possuem menos de 60 anos, assim, foram considerados neste estudo porque estão prestes a completar os 60 anos e fizeram questão de contribuir com a pesquisa.

Quanto aos idosos que participam dos grupos universitários, a maioria, 43 idosos (71\%), tem até 70 anos, entre os quais, a maior concentração está na faixa etária entre 50 e 65 anos, com um total de 26 idosos (43\%). Entretanto, destes, somente 7 idosos (23\%) ainda não completaram 60 anos, mas foram entrevistados porque manifestaram grande interesse em contribuir com a investigação. Esse dado revela que, assim como ocorre com os grupos da FASC, as pessoas estão buscando novas formas de relação e de socialização cada vez mais jovens, o que pode ser ocasionado pela existência de uma "nova geração" de idosos, mais dinâmica e inovadora, e pela própria mudança do significado social desses espaços sócio-ocupacionais.

\footnotetext{
6 Salienta-se que os nomes dos idosos entrevistados foram trocados pela letra "S" (de sujeito), seguida de um número (S1, S2, S3...), como forma de preservar o sigilo ético da pesquisa. Do mesmo modo, os nomes dos profissionais foram trocados pela letra $\mathrm{P}$ (de profissional), seguida de um número ( $\left.\mathrm{P}_{1}, \mathrm{P}_{2}, \mathrm{P}_{3}\right)$.
} 
A pesquisa realizada aponta uma grande desigualdade entre o nível de escolaridade dos idosos pertencentes aos grupos da FASC e o daqueles que frequentam os grupos universitários. Como é possível observar na tabela 1, a maioria, 40 idosos (67\%) dos grupos da FASC, tem apenas o ensino fundamental incompleto, sendo que, destes, 10 idosos (17\%) são analfabetos, diferentemente dos grupos universitários, nos quais a maioria, 40 idosos (66\%), cursou ensino médio ou ensino superior completo, e não existem analfabetos.

Tabela 1: Nível de escolaridade dos idosos que frequentam os grupos da FASC e grupos universitários (PUCRS e UFRGS)

\begin{tabular}{|c|c|c|c|c|c|}
\hline \multicolumn{3}{|c|}{ Grupos da FASC } & \multicolumn{3}{|c|}{ Grupos Universitários } \\
\hline Nível de Escolaridade & Sujeitos & $(\%)$ & Nível de Escolaridade & Sujeitos & (\%) \\
\hline Analfabeto & 10 & $17 \%$ & Analfabeto & - & - \\
\hline $\begin{array}{l}\text { Ens. Fundam. } \\
\text { Incompleto }\end{array}$ & 30 & $50 \%$ & $\begin{array}{l}\text { Ens. Fundam. } \\
\text { Incompleto }\end{array}$ & 7 & $12 \%$ \\
\hline $\begin{array}{c}\text { Ens. Fundam. } \\
\text { Completo }\end{array}$ & 14 & $23 \%$ & $\begin{array}{c}\text { Ens. Fundam. } \\
\text { Completo }\end{array}$ & 9 & $15 \%$ \\
\hline Ens. Médio & 3 & $5 \%$ & Ens. Médio & - & - \\
\hline Ens. Médio Completo & 3 & $5 \%$ & Ens. Médio Completo & 17 & $28 \%$ \\
\hline $\begin{array}{l}\text { Ens. Superior } \\
\text { Incompleto }\end{array}$ & - & - & $\begin{array}{l}\text { Ens. Superior } \\
\text { Incompleto }\end{array}$ & 4 & $7 \%$ \\
\hline $\begin{array}{c}\text { Ens. Superior } \\
\text { Completo } \\
\text { Mínimos }\end{array}$ & - & - & $\begin{array}{c}\text { Ens. Superior } \\
\text { Completo } \\
\text { Mínimos }\end{array}$ & 23 & $38 \%$ \\
\hline Total & 60 & $100 \%$ & & 60 & $100 \%$ \\
\hline
\end{tabular}

Fonte: KIST (2011).

Esses dados revelam que a necessidade de convívio social independe da renda e do nível de escolaridade. Evidenciam, também, que a população idosa, de um modo geral, representa uma parcela significativa da população total do Brasil com baixa escolaridade. Conforme os dados demográficos do IBGE (2010), 30,7\% da população brasileira possui menos de um ano de instrução e apenas $17,4 \%$ têm nove ou mais anos de estudo. Mesmo com a existência de avanços importantes nos níveis de escolaridade da população brasileira, observam-se diferenças significativas entre as regiões e os grupos etários. Considerando-se o período 


\section{temporalis}

de 1940 a 2000, observa-se um aumento de $59 \%$ do número de homens alfabetizados e de $146 \%$ no grupo das mulheres. Mesmo com o aumento importante do nível de escolaridade das mulheres, constata-se que elas ainda se encontram em desvantagem $(63 \%)$, se comparadas aos homens, que apresentam um percentual de $68,9 \%$ na melhora de suas condições de alfabetização (CAMARANO; KANSO; MELLO, 2004).

Constata-se que a renda significa um importante indicador do nível socioeconômico da população analisada e está diretamente relacionada com o nível de escolaridade da população. Assim como identificado no indicador escolaridade, observa-se uma distância muito elevada entre a condição de renda dos idosos pertencentes aos grupos da FASC e das universidades. Dos 60 idosos que integram os grupos universitários analisados, identifica-se que a maioria, $31(52 \%)$, possui renda mensal superior a 4 salários mínimos, 13 (21\%) recebem menos de um salário mínimo ou não possuem renda.

Já nos grupos da FASC, a maioria, 42 idosos (70\%), possui renda de até um salário mínimo, e 18 idosos (30\%) recebem de 2 a 5 salários mínimos, com uma concentração de 15 idosos (25\%) com renda entre 2 e 3 salários mínimos. A maior concentração de renda dos 120 idosos analisados, 41 (68\%), recebe até um salário mínimo, o que comprova que a maioria dos sujeitos analisados compõe o grupo de idosos brasileiros que recebem até um salário mínimo, correspondendo a 43,2\% desse grupo etário (IBGE, 2010).

\section{A participação social e a autonomia dos idosos}

A participação do idoso é um tema que merece especial atenção na atualidade e requer a compreensão de que ela pode representar interesses e preocupações antagônicas e sofrer influências de determinações sócio-históricas da realidade. Souza (2000) salienta que a participação é um processo social resultante da ação de forças sociais a partir de determinantes como o gênero, a classe, o grupo social, entre outros fatores, que possibilita a análise, a reflexão e a identificação de ações que contribuam para a satisfação de necessidades coletivas.

Como ressalta Marx (1975, p. 196), 
o homem - muito embora se revele assim como indivíduo particular, e é precisamente esta particularidade que dele faz um indivíduo e um ser comunal individual - é de igual modo a totalidade, a totalidade ideal, a existência subjetiva da sociedade enquanto pensada e sentida. Ele existe ainda na realidade como intuição e o espirito real da existência social, como uma totalidade de manifestação humana da vida.

A participação se constitui como um requisito para a realização e o desenvolvimento social do próprio ser humano (SOUZA, 2000). A participação efetiva em processos decisórios coletivos pressupõe a capacidade crítica e a autonomia dos sujeitos, condição essencial para o exercício da cidadania. Esta, por sua vez, implica um permanente aprendizado democrático dos sujeitos em uma sociedade organizada e reconhecida a partir de direitos e deveres individuais e coletivos. Participação, nessa perspectiva, significa um exercício democrático, pois “[...] através dela aprendemos a eleger, a deseleger, a estabelecer rodízio no poder, a exigir prestação de contas, a desburocratizar, a forçar os mandantes a servirem à comunidade, e assim por diante" (DEMO, 2001, p. 71).

Quando questionados sobre a importância da participação no grupo, tendo em vista sua autonomia, apenas 7 (6\%) dos idosos entrevistados revelaram acreditar que não existe nenhuma contribuição, em especial, sob a justificativa de que já se consideravam pessoas autônomas antes de sua inserção no grupo. Entretanto, 113 (94\%) afirmaram que o grupo possui um papel importante para a garantia de sua autonomia, pois Ihes possibilita um maior discernimento, um aprendizado que se constitui a partir de uma maior conexão com a realidade e das trocas coletivas, e a descoberta de que ainda é possível aprender e ensinar. Verifica-se um empenho dos idosos analisados na busca de novos conhecimentos que lhes proporcionem autorrealização e ampliem suas possibilidades de relação, conforme evidenciado em algumas falas dos sujeitos entrevistados.

Porque adquirir conhecimento faz com que a pessoa se posicione com firmeza, se tem base, argumentação, 


\section{temporalis}

para justificar teu ponto de vista. Agora, se vai ser aceito ou não, é outra coisa! (S. 39).

A gente nunca sabe tudo. Estamos aprendendo sempre! Muita coisa eu aprendi, outras eu ensinei. É uma troca! Para mim foi muito bom! (S. 75).

A educação possui uma grande importância na promoção de iniciativas comunitárias que permitam a participação dos idosos e favoreçam o seu protagonismo. A participação real do idoso no seu processo de aprendizagem somente é possível através da criação de espaços inclusivos que facilitem linguagens, estratégias e técnicas que permitem sua atuação, seu sentimento de utilidade, sua satisfação vital, sua realização pessoal e uma maior qualidade de vida (AMARÓs et al., 2006). Como enfatiza Irigaray (2004), o processo grupal propicia a manutenção da funcionalidade e da flexibilidade, aumenta a possiblidade de novas adaptações e de competências e colabora para mudanças do comportamento que contribuam para que o idoso enfrente de forma mais preparada e autônoma os desafios dessa fase da vida, conforme evidenciado nas falas de alguns entrevistados:

No momento em que se tem experiências diferentes, acabamos tendo posições mais firmes sobre determinados assuntos (S. 35).

Porque me sinto mais seguro, mais consciente do que posso fazer. Quando eu podia imaginar que com mais de 80 anos eu ia dançar, me apresentar no teatro? Isso é botar para fora o que se tem lá dentro! A gente se sente mais seguro, com autonomia mesmo! (S. 47).

A autonomia básica significa a "capacidade do indivíduo de eleger objetivos e crenças, de valorá-los com discernimento e de pô-los em prática sem opressões" (PEREIRA, 2002, p. 70). Essa capacidade vai sendo construída de forma processual e permanente pelos sujeitos, pois, como afirma Freire (1992, p. 107), "ninguém é autônomo primeiro para depois decidir". Conforme se observa no relato dos idosos entrevistados, a autonomia vai sendo constituída a partir das experiências e das decisões tomadas ao longo da vida, sendo que, muitas vezes, é somente na velhice e mediante o contato com outros idosos que participam do grupo que as pessoas encontram força e coragem para tomar 
suas próprias decisões e mudar o curso de suas vidas, conforme se observa no relato de algumas entrevistadas:

Eu era uma pessoa muito fechada e dependente do meu marido. Eu casei muito jovem, não trabalhava fora. Eu saí de um dono e fui para outro! Depois que eu vim para cá, comecei a me liberar, ver que tinham coisas que eu podia resolver sozinha. E tudo isso foi depois que eu vim para cá! Isso aí já estava dentro de mim, mas eu não conseguia botar para fora. Os grupos que eu ia antes não tinham nada a ver com a minha vida. Aqui eu me encontrei! (S. 54).

Eu converso com meus filhos, e hoje eles reconhecem a importância da minha participação no grupo e me respeitam. No começo, quando eu falava para eles sobre nossa proposta de implementar o "relógio biológico" aqui na Universidade, em especial com aquele que é médico, ele dizia: "Ah...". E sempre me perguntava: "Mas e a comprovação científica disso?". E hoje, ele já reconhece isso e me respeita (S. 56).

Agora, eu tomo as minhas próprias decisões. Antes, eu tinha que ficar perguntando pra um e pra outro o que tinha que fazer (S. 71).

A realização de processos de participação social de forma bem coordenada e orientada nos grupos pode contribuir para que ocorram mudanças significativas na vida dos sujeitos (BULLA; SOARES; KIST, 2008). O processo grupal permite que o idoso passe a viver mais de acordo consigo mesmo, reconhecendo seus direitos e assumindo suas responsabilidades e seu papel na sociedade, a partir de uma vida mais saudável, ativa e feliz, que comprova a existência de uma verdadeira autonomia:

Quando o coordenador não vem, a comissão é quem faz o grupo. A gente pensa em casa o que fazer. A minha vida mudou completamente, até minha saúde. Eu ainda vou fazer uma faculdade. Eu acredito naquilo que eu faço. Eu acho que a gente tem que acreditar que pode conseguir as coisas! Depois que a gente perde o marido a gente tem outra vida, é uma vida nova! Não que eu não goste dos filhos, mas é outro lado que eu não conhecia! É uma realização! (S. 86). 


\section{temporalis}

A autonomia individual somente é obtida mediante a capacidade de deliberar, a partir de necessidades e pontos de vista individuais, objetivando o atendimento das necessidades e interesses comuns, oportunizando escolhas coletivas. Ela pressupõe a existência de experiências e responsabilidades compartilhadas, pois é

[...] na interação com outras pessoas que o indivíduo aprende a viver em sociedade, a obedecer regras como expressões de vontade coletiva e a manter e reforçar objetivos e crenças. Tais regras constituem o parâmetro tanto de seu senso de pertencimento, como pessoa e como cidadão, como do reconhecimento, de sua parte de direitos e deveres dos outros (PEREIRA, 2002, p. 72).

Para Marx (1975, p. 203), um sujeito autônomo é aquele considerado como "dono de si mesmo" e, portanto, "quando a si mesmo deve a existência”. A conquista da autonomia pressupõe o reconhecimento social dos indivíduos, a consideração de suas necessidades e a valorização de suas potencialidades, uma vez que

[...] a ausência de experiências sociais de valorização e reconhecimento mútuo impede que os agentes sejam capazes de sustentar certas atitudes em relação a si mesmo, em particular, a autoconfiança (adquirida nas relações de amor e amizade), o autorrespeito (alcançado nas relações legalmente institucionalizadas de respeito pela dignidade e valor moral das pessoas) e a autoestima (construída nas redes de solidariedade e de valores compartilhados por meio das quais o valor particular dos membros de uma comunidade podem ser reconhecidos) (MARQUES; MAIA, 1997, p. 76).

A compreensão da autonomia requer uma definição conceitual sobre a dependência, que é identificada por Allué e Moragas (2003) como o resultado de limitações que podem aparecer a partir dos 60 ou $65^{7}$ anos e que originam déficits que podem provocar

7 As idades de 60 e 65 anos são cronologicamente definidas pela Organização Mundial de Saúde para distinguir a população idosa em países em vias de desenvolvimento e nos desenvolvidos, respectivamente. 
limitações no funcionamento normal do indivíduo. A dependência inicia com uma deficiência (perda de uma estrutura de função psicológica ou fisiológica), que pode passar a uma incapacidade (restrição da capacidade de realização de determinadas atividades de forma normal). Essa situação, por sua vez, pode passar à fase final do processo, que significa a impossibilidade de o indivíduo manter o papel normal correspondente a sua idade.

É importante que se diferencie conceitualmente a autonomia da independência e se tenha clareza de que a existência de uma delas não pressupõe a outra. Um indivíduo idoso pode ter condições de viver de forma independente, por seus próprios meios, mas ser impedido de tomar suas decisões e viver de modo autônomo. Por outro lado, um idoso que apresente uma situação de dependência pode, perfeitamente, viver de maneira autônoma, assumindo o comando e as decisões de sua própria vida, mesmo que necessite de ajuda para realizar suas atividades básicas e instrumentais da vida diária.

A esperança de vida saudável, em geral, é utilizada como sinônimo de esperança de vida livre de incapacidades e se constitui num indicador importante para avaliar o tempo em que as pessoas idosas podem viver sem incapacidades nas diferentes populações. A manutenção da autonomia e da independência é um desafio e um objetivo para a garantia do envelhecimento ativo, tanto para os indivíduos e as populações que envelhecem como para os responsáveis públicos. Prado (2006) ressalta a importância da eliminação de barreiras visíveis e invisíveis para a garantia da autonomia e da independência das pessoas idosas. Além de trabalhar as pessoas, é necessário dotar de flexibilidade os espaços (urbanos, edificações, transportes etc.), com indicações informativas que facilitem o acesso desse grupo etário e permitam sua mobilidade de forma independente.

A capacidade das pessoas idosas em manter sua independência e autonomia determina, em grande parte, a sua qualidade de vida. Fernández-Ballesteros (1997) ressalta que é muito difícil definir a qualidade de vida dos indivíduos, mas que há a possibilidade de se estabelecer uma de suas condições essenciais, a multidimensionalidade. Essa análise exige a existência de múltiplos 


\section{temporalis}

indicadores que contemplem as condições objetivas de vida, bem como as questões subjetivas (consciência), que incluam a reflexão e o conceito que cada indivíduo tem sobre elas. Nesse sentido, são analisados, por exemplo, aspectos relacionados com a saúde física, as habilidades funcionais, o estado pessoal e psicológico, o nível de independência, as crenças pessoais, os relacionamentos sociais, o tipo e o nível de atividades, a integração social, a satisfação com a vida, a qualidade ambiental (da própria residência e do entorno), os serviços sociais e de saúde, entre outros.

É bastante evidente a compreensão dos profissionais entrevistados neste estudo sobre a importância do grupo para a garantia da autonomia da população idosa, conforme evidenciado por 97\% deles. Esses profissionais revelam que, ao se trabalhar a capacidade funcional dos indivíduos, potencializando a aptidão física e mental, a saúde, a adoção de um estilo de vida ativo, a integração social, entre outros aspectos, essas pessoas se tornam independentes e autônomas, pois adquirem capacidade decisória e se tornam sujeitos de sua ação. Além disso, a participação no grupo propicia uma satisfação e uma realização pessoal que os converte em multiplicadores dos direitos sociais e motivadores do ingresso de outros idosos no grupo, como identificado nos relatos de alguns profissionais entrevistados.

A partir do momento em que nós, técnicos, começamos a trabalhar com elas, se observa que podem ter esta autonomia. Antes elas eram "monitoradas" e agora nós perguntamos: "Vocês querem fazer o quê?" (P. 30).

Na medida em que eles têm informação, eles se cuidam melhor, não adoecem e decidem melhor as coisas (P. 2).

Por exemplo, quando uma senhora diz: "eu viuvei e fiquei perdida" ou, "eu era o que o meu marido queria que eu fosse", não há dúvida, o grupo contribui para enfrentar a situação! (P. 16).

Conforme evidenciado neste estudo, é reconhecido que a participação do idoso no grupo contribui para a garantia de sua independência e de sua autonomia. Assim, compreende-se que a possibilidade de realizar as atividades da vida diária sem a 
necessidade da ajuda de outras pessoas, associada à capacidade de tomar suas próprias decisões, à existência de boas condições socioeconômicas, socioafetivas e de saúde, entre outros aspectos, constitui-se em importantes indicadores de que a participação grupal dos idosos também pode contribuir para a melhoria de sua qualidade de vida.

\section{CONSIDERAÇÕES SOBRE O TEMA}

A Organização Mundial de Saúde (OMS, 1998) alerta para a importância de se compreender o envelhecimento como um processo que tem duração em toda a vida, o que requer sua consideração mediante uma perspectiva que englobe todo o ciclo vital. A qualidade de vida social pressupõe a existência da saúde e da capacidade funcional dos indivíduos, sendo que esta é determinada a partir do nível de autonomia apresentado pelas pessoas para o atendimento de suas necessidades pessoais e da capacidade de se relacionar com os demais. O processo de envelhecimento está diretamente relacionado com as condições objetivas de vida de cada sujeito, que envolve aspectos como a classe social e a situação socioeconômica, o gênero, a formação, a procedência, a bagagem cultural, as relações familiares, a aposentadoria, a viuvez, as separações, as mudanças físicas e biológicas vivenciadas pelas pessoas com o aumento da idade e a experiência do limite expresso pelas doenças e pela proximidade da morte, entre outros fatores.

O fato de envelhecer está relacionado, também, com as experiências subjetivas, com as mudanças experimentadas, com os estilos de vida, com as formas com que a sociedade classifica e valoriza esses sujeitos. Todos esses fatores, no seu conjunto, são determinantes para a formação da identidade das pessoas e refletem no processo de desenvolvimento de seu ciclo vital, bem como evidenciam o seu modo de vida, que tem a ver com a maneira como cada indivíduo pensa, reage e se porta dentro do contexto social nas fases distintas de sua vida.

Torna-se cada vez mais evidente a importância do tempo livre para os processos de realização pessoal e de socialização e observa-se que os idosos têm buscado uma relação de equilíbrio entre eles (AMARÓS et al., 2006). Entretanto, há que se levar em 


\section{temporalis}

conta que a realização dessas atividades está condicionada por fatores econômicos, pelo nível cultural, pelo estado de saúde e pelos hábitos existentes antes dessa fase da vida. Nesse sentido, são extremamente importantes os programas educativos e universitários ofertados por órgãos públicos e privados, bem como as atividades grupais desenvolvidas a partir das Secretarias e/ou Departamentos de Assistência Social dos municípios, que permitem a inserção dos idosos em espaços coletivos como os grupos de convivência.

Constata-se que os idosos que participam dos grupos analisados em Porto Alegre obtêm resultados muito benéficos com sua participação, que se traduzem na oportunidade de uma vida de relação, de amizade, de companheirismo, de solidariedade e de pertencimento. Identifica-se, também, que a maioria desses usuários encontra-se em bom estado de saúde física e psicológica e busca nesses locais a possibilidade de suprir a perda de papéis sociais, obter uma forma de continuar sentindo-se útil e de colaborar com a sociedade.

A participação dos idosos nos grupos lhes proporciona uma compreensão da realidade atual, da fase da vida que estão vivenciando, de suas consequências nos relacionamentos familiares e sociais. Além disso, favorece o desenvolvimento de processos de revitalização pessoal que contribuem para evitar a solidão, situações de dependência e de invalidez física e mental, bem como novas experiências e uma melhora significativa na qualidade de sua vida.

Em que pese o reconhecimento de que a prioridade de atenção dos grupos da Fundação de Assistência Social e Cidadania é o idoso vulnerabilizado, diferentemente dos grupos universitários analisados, reafirma-se a tese da "Tese de Doutorado" (KIST, 2011, p. 220) que "consiste na convicção de que o idoso, enquanto um ser social, possui a necessidade de convivência independente de sua classe social, e que o grupo pode responder a essa necessidade". A partir da opção pelo método científico materialista, dialético e histórico, com base em Marx, que fundamentou o referido estudo, confirma-se que "o significado humano da natureza só existe para o homem social, porque só neste caso é que 
a natureza surge como laço com o homem, como existência de si para os outros e dos outros para si, e ainda como elemento vital da realidade humana: só aqui se revela como fundamento da própria experiência humana" (MARX, 1975, p. 194).

\section{REFERÊNCIAS}

ALLUÉ, Ramón Cristòfol; MORAGAS, Ricardo Moragas (Org.). El coste de la dependencia al envejecer. Barcelona: Herder S. L., 2003.

AMARÓS, P. et al. Construyendo futuro: las personas mayores: una fuerza social emergente. Madrid: Alianza Editorial, 2006.

BARDIN, Lourence. Análise do Conteúdo. Lisboa: Edições 70, 1977.

BRASIL. Lei que regulamenta a profissão de Assistente Social (1993). Lei n. 8662/1993. In: CONSELHO REGIONAL DE SERVIÇO SOCIAL (CRESS) 11 $1^{a}$ REGIÃO. Coletânea de Legislações: Direitos de Cidadania. Edição Especial do II Congresso Paranaense de Assistentes Sociais. Curitiba: CRESS 10ª 2003. p. 06-12.

BULLA, L. C; SOARES, E. S.; KIST, R. B. B. Cidadania, pertencimento e participação social de idosos. Grupos Trocando Ideias e Matinê das Duas: Cine Comentado. Revista Ser Social 21, Brasília, p. 169-196, 2008.

CAMARANO, A. A. KANSO, S.; MELLO, J. L. Como vive o idoso brasileiro? In: CAMARANO, A. A. (Org.) Os novos idosos brasileiros: muito além dos 60? Rio de Janeiro: IPEA, 2004. p. 25-73.

CARVALHO, Denise Bomtempo Birche; SILVA, Maria Ozanira da Silva (Org.). Serviço Social, Pós-Graduação e produção de conhecimento no Brasil. São Paulo: Cortez, 2005.

CONSELHO FEDERAL DE SERVIÇO SOCIAL (CFESS). Código de Ética Profissional do Assistente Social (1993). Resolução CFESS n. 273/1993. In: CONSELHO REGIONAL DE SERVIÇO SOCIAL (CRESS) $11^{a}$ REGIÃO. Coletânea de Legislações: Direitos de Cidadania. 


\section{temporalis}

Edição Especial do II Congresso Paranaense de Assistentes Sociais. Curitiba: CRESS 10 a 2003. p. 13-24.

CONSELHO NACIONAL DE SAÚDE. Resolução CNS n. 196/1996.

Disponível em: <http://conselho.saude.gov.br/web_comissoes/ conep/aquivos/resolucoes/resolucoes.htm>. Acesso em: 9 fev. 2014.

CONSELHO NACIONAL DE SAÚDE. Resolução CNS n. 251/1997. Disponível em: <http://conselho.saude.gov.br/web_comissoes/ conep/aquivos/resolucoes/resolucoes.htm>. Acesso em: 9 fev. 2014.

COUTO, Berenice Rojas. Formulação de projeto de trabalho profissional. In: CONSELHO FEDERAL DE SERVIÇO SOCIAL; ASSOCIAÇÃO BRASILEIRA DE ENSINO E PESQUISA EM SERVIÇO SOCIAL. Serviço Social: direitos sociais e competências profissionais. Brasília: CFESS/ABEPSS, 2009. p. 651-663.

CURY, Carlos R. Jamil. Educação e Contradição. São Paulo: Cortez, 1985.

DEMO, Pedro. Participação é conquista: noções de política social. 5. ed. São Paulo: Cortez, 2001.

FERNÁNDEZ-BALLESTEROS, Rocío. Calidad de vida en la vejez: condiciones diferenciales. Anuario de Psicología, Barcelona, n. 73., p. 89-104, 1997.

FREIRE, Paulo. Pedagogia da esperança: um reencontro com a Pedagogia do oprimido. 6. ed. Rio de Janeiro: Paz e Terra, 1992.

GUERRA, Yolanda. A dimensão investigativa no exercício profissional. In: CONSELHO FEDERAL DE SERVIÇO SOCIAL; ASSOCIAÇÃO BRASILEIRA DE ENSINO E PESQUISA EM SERVIÇO SOCIAL. ServiçO Social: direitos sociais e competências profissionais. Brasília: CFESS/ABEPSS, 2009. p. 701-717.

INSTITUTO BRASILEIRO DE GEOGRAFIA E ESTATÍSTICAS. IBGE. Sinopse do Censo Demográfico 2010. Rio de Janeiro: IBGE, 2011. 
. Síntese de Indicadores Sociais: uma análise das Condições de Vida da População brasileira 2007. Estudos e Pesquisas, Informação demográfica e socioeconômica n. 21. Rio de Janeiro: IBGE, 2007.

. Síntese de Indicadores Sociais: uma análise das Condições de Vida da População brasileira 2008. Estudos e Pesquisas, Informação demográfica e socioeconômica n. 23. Rio de Janeiro: IBGE, 2008.

. Síntese de Indicadores Sociais: uma análise das Condições de Vida da População brasileira 2010. Estudos e Pesquisas, Informação demográfica e socioeconômica n. 27. Rio de Janeiro: IBGE, 2010.

IRIGARAY, Tatiana Quarti. Envelhecendo e Aprendendo. In: CASTRO, Odair Perugini (Org.). Envelhecer: revisitando o corpo. Sapucaia do Sul: Notadez, 2004. p. 55-67.

KIST, Rosane Bernardete Brochier. Os Grupos de Convivência em Porto Alegre e sua contribuição à garantia de direitos e à autonomia de homens e mulheres idosos: uma aproximação com os Centros de Idosos em Barcelona. 2011. Tese (Doutorado em Serviço Social) - Pontifícia Universidade Católica do Rio Grande do Sul, Porto Alegre, 2011.

MARCONI, M. A.; LAKATOS, E. M. Técnicas de Pesquisa. 6. ed. São Paulo: Atlas S.A., 2006.

MARQUES, A. C. S.; MAIA, R. C. M. Dimensões da autonomia no combate à pobreza: O Programa Bolsa-Família sob a perspectiva das beneficiárias. Revista Serviço Social e Sociedade, São Paulo, n. 92, p. 58-84, 2007.

MARX, Karl. Manuscritos Econômico-Filosóficos. Lisboa: Edições 70, 1975. 